\title{
Simultaneous determination of 13 mycotoxins in feedstuffs using QuEChERS extraction
}

\author{
Hyeong-Wook Jo ${ }^{1 \dagger}$, Min-Kyu Park ${ }^{2 \dagger}$, Hyo-min Heo ${ }^{1}$, Hwang-Ju Jeon ${ }^{3}$, Sung-Deuk Choi ${ }^{2^{*}+}$, Sung-Eun Lee ${ }^{3^{* \dagger}}$ and \\ Joon-Kwan Moon ${ }^{4 *}$
}

\begin{abstract}
Mycotoxins are secondary metabolites produced by various fungi and are known to have a significant negative impact on human and animal health. When feedstuffs are contaminated with mycotoxins, their toxicities may be caused a variety of diseases. In this study, the residual mycotoxins in feedstuffs were analyzed using LC-MS/MS incorporated with QuEChERS extraction. Analytical method validation was performed for LOD, LOQ, linearity, and recoveries with consideration of matrix effects prior to the residual analysis. They were all reached to the accepted range of validation level. Using 39 feedstuff samples $(5 \mathrm{~g})$ for mycotoxin analysis, nine samples were contaminated by four major mycotoxins such as fumonisin B1 (FB1), deoxynivalenol, fumonisin B2, and zearalenone. Among them, FB1 was detected at the highest concentration as $18.0943 \mathrm{mg} / \mathrm{kg}$. The total sum of fumonisins in 39 samples did not exceed the maximum residual level (MRL) criterion set by Korean Food and Drug Administration. Altogether, intensive management of mycotoxins in Korean feedstuffs should be implemented with proper and routine monitoring, even their residual concentrations are not exceeded over the MRL levels because of high frequent detection found in this study.
\end{abstract}

Keywords: Mycotoxins, QuEChERS, LC-MS/MS, Feedstuffs, Fumonisines

\section{Introduction}

Mycotoxins are natural compounds produced by various fungi and that cause various diseases in humans and livestock [1-4]. Aflatoxins (AFs) and ochratoxins (OTs) are representative examples produced with well-known fungi and their biosynthetic mechanisms are well understood

\footnotetext{
*Correspondence: sdchoi@unist.ac.kr; selpest@knu.ac.kr; jkmoon264@gmail. com

${ }^{\dagger}$ Hyeong-Wook Jo and Min-Kyu Park equally contributed to this paper as the first author

†'Sung-Deuk Choi, Sung-Eun Lee and Joon-Kwan Moon equally contributed to this paper

${ }^{2}$ School of Urban and Environmental Engineering, Ulsan National Institute of Science and Technology (UNIST), Ulsan 44919, Republic of Korea

${ }^{3}$ Department of Applied Biosciences, Kyungpook National University, Daegu 41566, Republic of Korea

${ }^{4}$ Department of Plant Life and Environmental Sciences, Hankyong National University, Anseong 17579, Republic of Korea

Full list of author information is available at the end of the article
}

$[5,6]$. Three primary strategies are used in agricultural and food industries to properly manage such mycotoxins, and they are physical-based control method, chemical-supporting control procedures, and biologically suppressed methods on the fungi growth.

Physical strategies typically use irradiation, such as gamma-rays $[7,8]$. Chemical controls include the application of fungicides $[9,10]$, use of chemical preservatives $[11,12]$, and new treatments with natural products [11, $13,14]$. Direct chemical degradation of mycotoxins is reported [15]. As an example, the decomposition of aflatoxin using ammonia is a well-known method to remove the toxin from peanuts and corn $[16,17]$. Efficient biological controls use competition with atoxigenic fungi as biocontrol agents [18], suppression of mycotoxin production with other microbial strains [19], and decomposition of mycotoxins with microbes [20]. 
A second critical aspect of mycotoxin management is adequate monitoring through multi-component simultaneous analysis to quickly and inexpensively analyze toxins in agricultural products and foods [21, 22]. Such analysis has recently been developed and introduced in various countries and is directly used for mycotoxin monitoring [21, 22]. Simultaneous analysis of mycotoxins needs to be accompanied with an effective mycotoxin extraction method with procedures, such as immunoaffinity or QuEChERS [21-23].

The third aspect of management is the development of adequate standards for acceptable mycotoxin limits for humans and livestock [24]. Various issues must be considered at the national level since each country establishes its own standards for tolerable intake levels [25]. Food types consumed are diverse, and quantities consumed of different foods vary widely, especially between Asian countries and European countries [24, 25].

Mycotoxin contamination analysis in agricultural products and feedstuffs is regularly conducted at the national level to check actual contamination levels, predict temporal variation, and understand relationships between mycotoxin generation and climatic conditions. Significant differences in the regional occurrence of mycotoxins are observed [26, 27]. With this regard, a simultaneous analysis method was developed for faster and cheaper determination of multiple mycotoxins in feedstuffs because single compound analysis took several disadvantages including analytical time consumption and expensive analytical cost. In this study, an extraction method was employed as quick, easy, cheap, effective, rugged, and safe (QuEChERS) extraction for lowering analytical cost, and thirteen different mycotoxins in feedstuffs analyzed using LC-MS/MS were developed to reduce analytical time consumption. Successful analytical procedures on the multiple mycotoxins at the same time were introduced with acceptable method validation results and higher efficient QuEChERS extraction level.

\section{Materials and methods Chemical and reagents}

Methanol $(\mathrm{MeOH})$ and acetonitrile $(\mathrm{MeCN})$ were purchased from Honeywell (Muskegon, MI, USA). Ammonium formate $(\geq 99.0 \%)$ was purchased from Sigma-Aldrich (St. Louis, MO, USA). Primary-Secondary-Amine (PSA bonded silica) was purchased from Supelco (Bellefonte, PA, USA). $\mathrm{C}_{18}$ end-capped resin was purchased from Agilent (Santa Clara, CA, USA). Formic acid $(99.0 \%$, GR) was purchased from Samchun Chemical Co. (Gyeonggi-do, Korea). Formic acid (LiChropur $\left.{ }^{\circledR}\right)$ was purchased from Merck (Darmstadt, Germany). Other chemicals used in this study were analytical grades.

\section{Preparation of standard solution}

The certified standards of mycotoxins were also purchased from Cfm Oskar Tropitzsch GmbH (Marktredwitz, Germany). Standard stock solutions of mycotoxins were prepared by dissolving each mycotoxin in distilled water/MeOH $(50 / 50, v / v)$. Working standard solutions were then diluted with $\mathrm{MeCN}$ for the calibration curve. Solutions were then kept in the dark at $-20{ }^{\circ} \mathrm{C}$ in amber glass vials before use.

\section{Samples}

For sample preparation, bean and maize were purchased from local markets in Ansung (Gyeonggi-do, Korea). Beans were blended and homogenized to a powder-like consistency. Maize as raw kernels were dried at $50{ }^{\circ} \mathrm{C}$ for one day, then blended and homogenized. All samples were kept at $-20^{\circ} \mathrm{C}$ until use.

\section{QuEChERS sample preparation Extraction}

For all tested samples, five grams $(5.0 \mathrm{~g} \pm 0.1 \mathrm{~g})$ of the freeze-dried samples were accurately weighed and transferred into $50 \mathrm{~mL}$ conical tubes. The weighed sample was extracted in $10 \mathrm{~mL}$ of a solution of $10 \%$ formic acid in $\mathrm{H}_{2} \mathrm{O}$ $(10 / 90, \mathrm{v} / \mathrm{v})$, and $10 \mathrm{~mL} \mathrm{MeCN}$ by shaking on a mechanical wrist shaker for $30 \mathrm{~min}$. After extraction, samples were treated with salt 1 (4 $\mathrm{g}$ anhydrous magnesium sulfate and $1 \mathrm{~g}$ sodium chloride), salt 2 (4 g anhydrous magnesium sulfate, $1 \mathrm{~g}$ sodium chloride, $1 \mathrm{~g}$ trisodiumcitrate dihydrate and $0.5 \mathrm{~g}$ disodium hydrogencitrate sesquihydrate), or with salt 3 (6 g anhydrous magnesium sulfate and $1.5 \mathrm{~g}$ sodium acetate), and shaken for $1 \mathrm{~min}$. Extracted samples were then centrifuged at 4,000 rpm for $10 \mathrm{~min}$.

\section{Cleanup}

One $\mathrm{mL}$ of supernatant from extract after centrifugation was vortexed with $25 \mathrm{mg} \mathrm{C}_{18}$ (powder type) and $25 \mathrm{mg}$ PSA (powder type) for $1 \mathrm{~min}$. Then, it was centrifuged at $10,000 \mathrm{rpm}$ for $5 \mathrm{~min}$ at $4^{\circ} \mathrm{C}$. Four hundred $\mu \mathrm{L}$ aliquots of supernatant were transferred to a microtube and mixed with $500 \mu \mathrm{L}$ distilled water and $100 \mu \mathrm{L} \mathrm{MeCN}$. This solution was stored at $4{ }^{\circ} \mathrm{C}$ for $30 \mathrm{~min}$. Samples solutions were passed through a $0.20 \mu \mathrm{m}$ and $4 \mathrm{~mm}$ polytetrafluoroethylene (PTFE) syringe filter (Hyundai Micro, Seoul, Korea), before analysis using the LC-MS/MS system.

\section{LC-MS/MS analysis}

An Agilent ultrahigh-performance liquid chromatography (UPLC) system (1290 Infinity, 1290 high-speed pump; G7120A, 1290 multisampler; G7167B, MCT; G71166B, Agilent, Santa Clara, CA, USA) was used to perform reverse-phase chromatographic separation of 13 mycotoxins. The separation used a Zorbax Eclipse Plus $\mathrm{C}_{18}$ column 
$(50 \mathrm{~mm} \times 2.1 \mathrm{~mm}$ i.d., $1.8 \mu \mathrm{m}$ particle size, Agilent, Santa Clara, CA, USA). The mobile phase employed a timeprogrammed gradient system using $\mathrm{H}_{2} \mathrm{O}$ (solvent $\mathrm{A}$ ) and $\mathrm{MeOH}$ (solvent B); both solvents contained $5 \mathrm{mmol} / \mathrm{L}$ ammonium formate and $0.1 \%(\mathrm{v} / \mathrm{v})$ formic acid. Gradient elution was initiated with $95 \%$ A for $1.5 \mathrm{~min}$. Solvent B was then linearly increased to $30 \%$ over $2.5 \mathrm{~min}$, and $60 \%$ within 4 min. B was further gradually increased to $80 \%$ within $5 \mathrm{~min}, 99 \%$ within $6 \mathrm{~min}$, then kept constant for $8.5 \mathrm{~min}$. Finally, B was decreased linearly to $5 \%$ over $8.6 \mathrm{~min}$ and equilibrated for $4.4 \mathrm{~min}$. The flow rate was $350 \mu \mathrm{L} / \mathrm{min}$.

The LC system was coupled with an Agilent $6470 \mathrm{TQ}$ mass spectrometer (Santa Clara, CA, USA) equipped with an AJS ESI source operation in positive and negative ionization mode. ESI-MS/MS was performed with dynamic multiple reaction monitoring. MassHunter Version 10.0 (Santa Clara, CA, USA) was used to control the UPLC-MS/MS system. Gas temperature, gas flow, nebulizer, sheath gas temperature, sheath gas flow, and capillary voltage were set at $300{ }^{\circ} \mathrm{C}, 7 \mathrm{~L} / \mathrm{min}, 35 \mathrm{psi}, 350{ }^{\circ} \mathrm{C}, 11$
L/min, and 3500 V, respectively. Fragmentation and collision energy levels were optimized for each precursor ion and different product ions. For each compound, at least one precursor, and one product ion for both identification and quantification purposes were determined, selecting the most abundant product ion for quantification and the second one for confirmation. The precursor ion and optimized MS/MS parameters (fragment and collision energy) for each mycotoxin are summarized in Table 1.

\section{Validation of method performance Linearity}

Linearity was evaluated by preparing calibration curve with five concentrations. Concentration ranges for mycotoxins are provided in Additional file 1: Table S1. Matrixmatched calibration curves were prepared for all two validated matrices, and solutions for matrix-matched calibration is reported in Additional file 1: Table S2.

Table 1 Optimized LC-MS/MS parameters for the determination of mycotoxins in feedstuffs

\begin{tabular}{|c|c|c|c|c|c|c|c|}
\hline Mycotoxin & $\begin{array}{l}\text { Retention } \\
\text { Time (min) }\end{array}$ & Ionization & $\begin{array}{l}\text { Precursor ion } \\
(\mathrm{m} / \mathrm{z})\end{array}$ & $\begin{array}{l}\text { Product lon } \\
(\mathrm{m} / \mathrm{z})\end{array}$ & $\begin{array}{l}\text { Fragment voltage } \\
(\mathrm{V})\end{array}$ & $\begin{array}{l}\text { Collision energy } \\
(\mathrm{V})\end{array}$ & $\begin{array}{l}\text { Cell } \\
\text { accelerator } \\
\text { voltage }(\mathrm{V})\end{array}$ \\
\hline \multirow[t]{2}{*}{ Aflatoxin $B_{1}$} & 4.53 & {$[\mathrm{M}+\mathrm{H}]^{+}$} & 313.0 & 285.0 & 175 & 25 & 5 \\
\hline & & & & 241.0 & & 40 & \\
\hline \multirow[t]{2}{*}{ Aflatoxin $B_{2}$} & 4.42 & {$[\mathrm{M}+\mathrm{H}]^{+}$} & 315.0 & 259.0 & 185 & 35 & 5 \\
\hline & & & & 287.0 & & 35 & \\
\hline \multirow[t]{2}{*}{ Aflatoxin $\mathrm{G}_{1}$} & 4.29 & {$[\mathrm{M}+\mathrm{H}]^{+}$} & 329.0 & 243.0 & 130 & 30 & 5 \\
\hline & & & & 311.0 & & 20 & \\
\hline \multirow[t]{2}{*}{ Aflatoxin $G_{2}$} & 4.16 & {$[\mathrm{M}+\mathrm{H}]^{+}$} & 330.9 & 313.0 & 160 & 25 & 5 \\
\hline & & & & 245.0 & & 35 & \\
\hline \multirow[t]{2}{*}{ Deoxynivalenol } & 3.04 & {$[\mathrm{M}+\mathrm{H}]^{+}$} & 297.3 & 249.1 & 109 & 10 & 5 \\
\hline & & & & 191.0 & & 58 & \\
\hline \multirow[t]{2}{*}{ Fumonisin $B_{1}$} & 5.08 & {$[\mathrm{M}+\mathrm{H}]^{+}$} & 722.0 & 352.3 & 180 & 45 & 5 \\
\hline & & & & 704.2 & & 40 & \\
\hline \multirow[t]{2}{*}{ Fumonisin $B_{2}$} & 5.53 & {$[\mathrm{M}+\mathrm{H}]^{+}$} & 706.4 & 335.9 & 180 & 35 & 5 \\
\hline & & & & 354.3 & & 30 & \\
\hline \multirow[t]{2}{*}{ Ochratoxin A } & 5.49 & {$[\mathrm{M}+\mathrm{H}]^{+}$} & 404.1 & 238.9 & 100 & 25 & 5 \\
\hline & & & & 192.7 & & 50 & \\
\hline \multirow[t]{2}{*}{ T-2 toxin } & 5.31 & {$\left[\mathrm{M}+\mathrm{NH}_{4}\right]^{+}$} & 483.8 & 215.0 & 140 & 20 & 5 \\
\hline & & & & 263.1 & & 10 & \\
\hline \multirow[t]{2}{*}{ HT-2 toxin } & 5.05 & {$\left[\mathrm{M}+\mathrm{NH}_{4}\right]^{+}$} & 442.5 & 263.1 & 120 & 10 & 5 \\
\hline & & & & 215.1 & & 10 & \\
\hline \multirow[t]{2}{*}{ Zearalenone } & 5.55 & {$[\mathrm{M}-\mathrm{H}]^{-}$} & 317.0 & 175.1 & 120 & 25 & 5 \\
\hline & & & & 186.9 & & 15 & \\
\hline \multirow[t]{2}{*}{ a-zearalenol } & 5.38 & {$[\mathrm{M}-\mathrm{H}]^{-}$} & 319.0 & 275.2 & 145 & 25 & 5 \\
\hline & & & & 301.1 & & 25 & \\
\hline \multirow[t]{2}{*}{$\beta$-zearalenol } & 5.16 & {$[\mathrm{M}-\mathrm{H}]^{-}$} & 319.0 & 275.2 & 145 & 25 & 5 \\
\hline & & & & 301.1 & & 25 & \\
\hline
\end{tabular}




\section{Matrix effect}

The evaluation of signal suppression/enhancement due to matrix effects was calculated with the following equation from five point calibration curves.

$$
\begin{aligned}
& \text { Matrix effect }(\%) \\
& \quad=100 \times \text { slope }_{\text {matrix }- \text { matched standard calibration }} \\
& \text { /slope } \\
& \text { solvent standard calibration }
\end{aligned}
$$

\section{Recovery}

Recovery was assessed following SANTE/11813/2017 and CODEX guidelines with replicated spiking experiments $(n=5)$ with 2MLOQ, 4MLOQ, and 20MLOQ levels for each mycotoxin. Average recovery values were calculated, and standard deviations for repeatability from five replicates were obtained as a measure of precision.

Retention times of analytes in sample extracts that correspond to the average of the calibration standards measured in same analytical sequence with a tolerance of $\pm 0.1 \mathrm{~min}$; ion ratios (defined as the response of the peak with the lower area divided by the response of the peak with the higher area) was calculated to be within $\pm 30 \%$ (relative) to that obtained from the average of the calibration standards from the same sequence. The employed sample preparation for the analysis of mycotoxins are summarized in Additional file 1: Figure S1.

\section{Results and discussion}

\section{LC-MS/MS optimization}

The optimization of the LC-MS/MS parameters used the optimizer program. Formation of a protonated precursor ion or ammonium adducts formic acid and ammonium formate was added to mobile phases. For T-2 toxin and HT-2 toxin, ammonium adducts were selected as precursor ions. For other components, protonated $\mathrm{m} / \mathrm{z}$ were chosen as precursor ions (Table 1). Ten mycotoxins were optimized in positive ESI mode and three mycotoxins, zearalenone (ZEN), $\alpha$-zearalenol ( $\alpha$-ZEA), and $\beta$-zearalenol ( $\beta$-ZEA), in negative mode (Fig. 1). These ionization products are quite different from a previous report [21] since these authors used negative mode for nivalenol (NIV), deoxynivalenol (DON), and deoxynivalenol-3-glucoside (D3G).

Peak intensity of the final dilution solution was tested using different values in distilled water, $5 \% \mathrm{HCOOH}$ in distilled water, $10 \% \mathrm{HCOOH}$ in distilled water, and $\mathrm{HCOOH} /$ $\mathrm{NH}_{4} \mathrm{COOH}$. No significant differences were observed (Additional file 1: Table S3). For identification purposes, the two most intense transition ions among precursor ions were selected; for mycotoxin quantification, only the most intense peak (quantifier) was used. Also, retention time (RT) and ion ratio (IR) variations measured in the samples met requested criteria ( $\pm 0.1 \mathrm{~min}$ for $\mathrm{RT}$ and $\pm 30 \%$ for IR), when compared with values obtained for calibration standards.

Another study reported similar findings for optimization of mycotoxin determination using LC-MS/MS, though retention times of mycotoxins were somewhat late compared our current result (Table 1) [21]. These authors used different eluting solutions with lower formic acid content. Different studies often develop their own optimal analytical system for determining mycotoxins.

\section{Extraction and cleanup step}

To obtain high extraction efficiency, three extraction solutions, Salt 1, 2, and 3, were compared, and extraction with Salt 1 and 2 showed similar extraction effectiveness, but Salt 3 was less efficient (Table 2). For fumonisins (FUMs) and ochratoxin A that include a carboxylic acid moiety, $10 \%$ formic acid was used in distilled water to decrease $\mathrm{pH}$. The $\mathrm{pH}$ of extraction solutions (Salt 1; pH 1.89 , Salt $2 ; \mathrm{pH} 2.24$, and Salt $3 ; 2.86$ ) was compared. Salt 1 solution, displaying the lowest $\mathrm{pH}$, was selected for extracting mycotoxins in this study.

For adequate cleanup efficiency, three absorbents, anhydrous $\mathrm{MgSO}_{4}, \mathrm{C}_{18}$, and PSA were compared. Each absorbent was used at the amount of 25 and $50 \mathrm{mg}$. In Table 3, when only acetonitrile was used, anhydrous $\mathrm{MgSO}_{4}$ and $\mathrm{C}_{18}$ were absorbed and were properly detected. As it contains carboxylic moiety, it is likely to absorb mycotoxins. However, fumonisin $B_{1}$ and $B_{2}$ were not absorbed by these two absorbents, while $\mathrm{C}_{18}$ efficiently absorbed all tested mycotoxins. For zearalenone, $\alpha$-zearalenol, and $\beta$-zearalenol, PSA absorbents showed a recovery lower than the acceptable range of $70-120 \%$ (Table 3).

Conversely, adsorption rate for each mycotoxin varied between extraction steps using $\mathrm{MgSO}_{4}$ and PSA (Additional file 1: Table S4). However, adsorption pattern by these two absorbents towards mycotoxins were so similar. However, anhydrous $\mathrm{MgSO}_{4}$ was used often to remove $\mathrm{H}_{2} \mathrm{O}$, and thus would be better to be excluded from cleanup procedure. Therefore, $25 \mathrm{mg}$ PSA was selected for the cleanup step as an adsorbent.

Three purification and extraction methods have been applied for mycotoxins and the first method is to use a solid phase extraction (SPE) column [21]. These authors used SPE column (Isolute column, Myco, Biotage, Sweden) to separate and purify mycotoxins from Korean soybean paste, and this method is easy to handle, inexpensive, and does not require any special storage condition. The second method is related to use QuEChERS materials $[21,23,28]$, and this method successfully separates and extracts mycotoxins from various matrices 


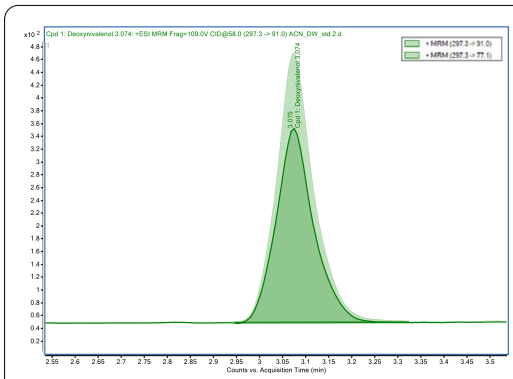

Deoxynivalenol $40 \mu \mathrm{g} / \mathrm{L}$

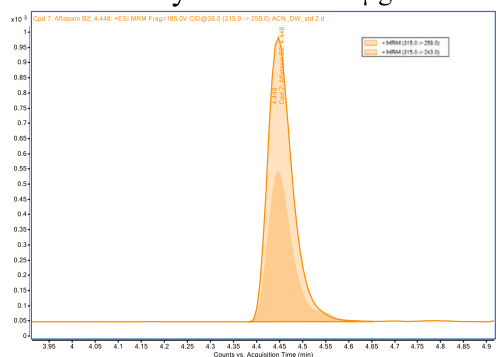

Aflatoxin $\mathrm{B}_{2} 2.0 \mu \mathrm{g} / \mathrm{L}$

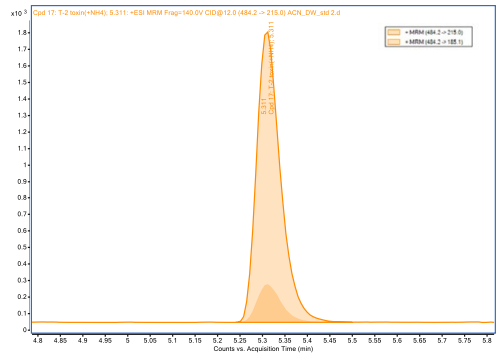

$\mathrm{T}-2$ toxin $40 \mu \mathrm{g} / \mathrm{L}$

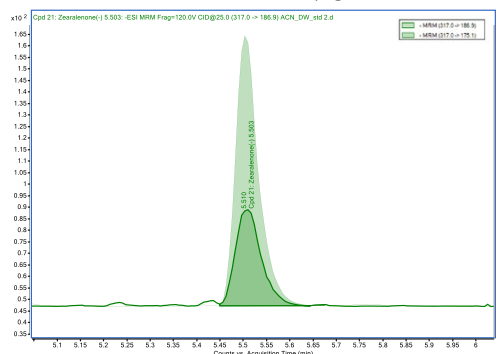

Zearalenone $10 \mu \mathrm{g} / \mathrm{L}$

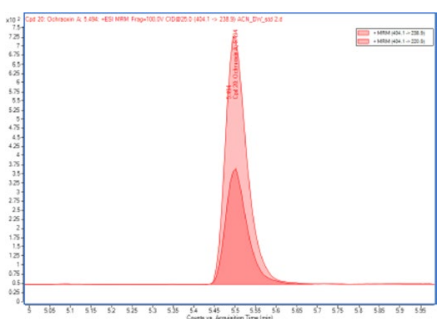

Ochratoxin A $8 \mu \mathrm{g} / \mathrm{L}$

Fig. 1 Qualitative and quantitative ion chromatograms of 13 mycotoxin analytes used in this study using LC-MS/MS

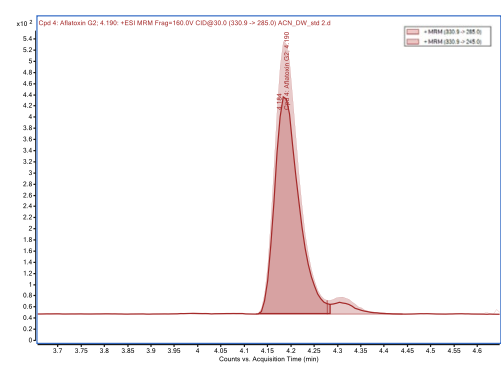

Aflatoxin $\mathrm{G}_{2} 2.0 \mu \mathrm{g} / \mathrm{L}$

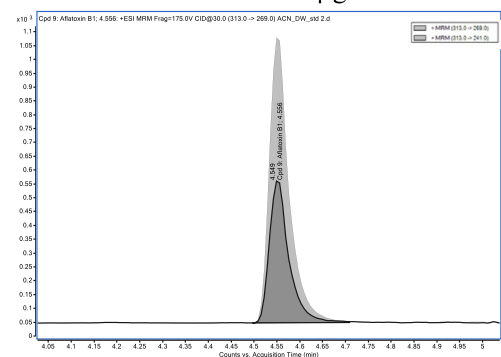

Aflatoxin $\mathrm{B}_{1} 2.0 \mu \mathrm{g} / \mathrm{L}$

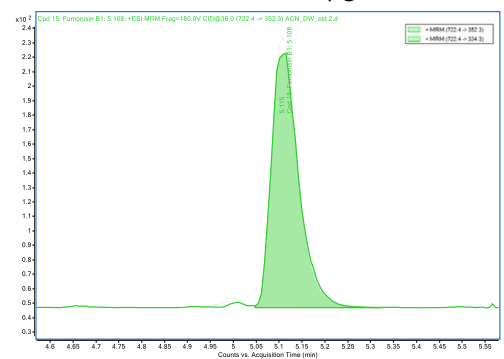

Fumonisin $\mathrm{B}_{1} 40 \mu \mathrm{g} / \mathrm{L}$

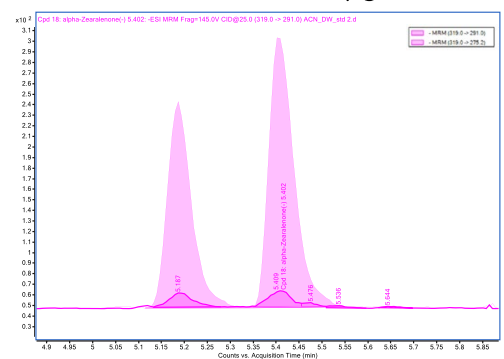

$\alpha$-Zearalenol $40 \mu \mathrm{g} / \mathrm{L}$

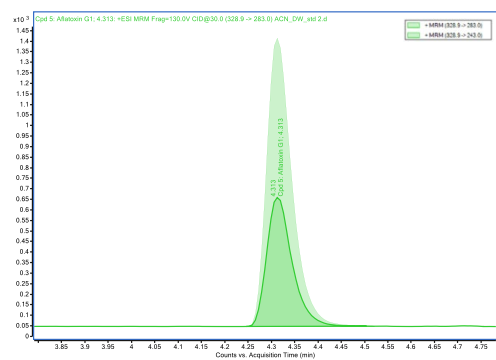

Aflatoxin $\mathrm{G}_{1} 2.0 \mu \mathrm{g} / \mathrm{L}$

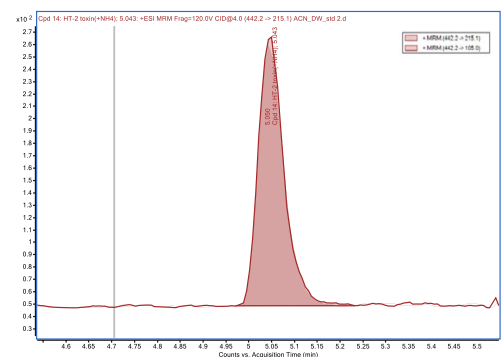

HT-2 toxin $40 \mu \mathrm{g} / \mathrm{L}$

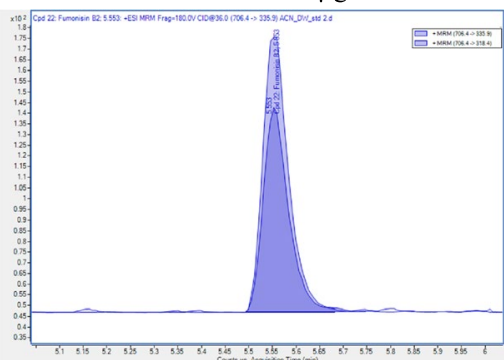

Fumonisin $\mathrm{B}_{2} 40 \mu \mathrm{g} / \mathrm{L}$

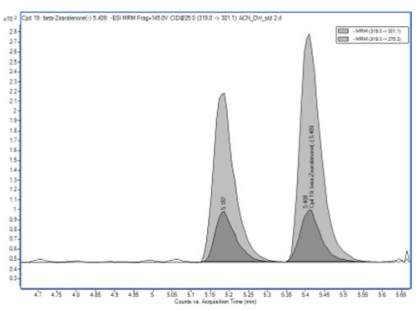

$\beta$-Zearalenol $40 \mu \mathrm{g} / \mathrm{L}$ 
Table 2 Efficiency of different extraction salt system towards mycotoxins

\begin{tabular}{|c|c|c|c|c|c|c|c|}
\hline \multirow[t]{3}{*}{ Mycotoxin } & \multirow{3}{*}{$\begin{array}{l}\text { Fortification Level } \\
(\mu \mathrm{g} / \mathrm{kg})\end{array}$} & \multicolumn{6}{|c|}{ Recovery (\%) } \\
\hline & & \multicolumn{2}{|l|}{ Salt 1} & \multicolumn{2}{|l|}{ Salt 2} & \multicolumn{2}{|l|}{ Salt 3} \\
\hline & & Average & $\%$ RSD & Average & $\%$ RSD & Average & $\%$ RSD \\
\hline Aflatoxin $B_{1}$ & 5 & 92.62 & 1.20 & 96.16 & 2.39 & 88.09 & 1.06 \\
\hline Aflatoxin $B_{2}$ & 5 & 80.21 & 1.65 & 82.05 & 0.87 & 75.51 & 2.11 \\
\hline Aflatoxin $\mathrm{G}_{1}$ & 5 & 78.40 & 1.12 & 81.40 & 0.42 & 73.15 & 1.82 \\
\hline Aflatoxin $G_{2}$ & 5 & 79.30 & 0.77 & 80.43 & 2.08 & 74.05 & 3.06 \\
\hline Deoxynivalenol & 100 & 77.68 & 1.49 & 82.74 & 0.49 & 74.95 & 0.69 \\
\hline Fumonisin $B_{1}$ & 100 & 74.76 & 3.40 & 79.32 & 3.20 & 72.13 & 0.45 \\
\hline Fumonisin $B_{2}$ & 100 & 78.59 & 0.95 & 82.27 & 0.72 & 71.87 & 1.47 \\
\hline Ochratoxin A & 20 & 78.86 & 1.73 & 80.71 & 1.95 & 71.81 & 2.54 \\
\hline T-2 toxin & 100 & 78.73 & 1.91 & 81.65 & 2.27 & 73.90 & 2.51 \\
\hline HT-2 toxin & 100 & 78.73 & 1.91 & 81.65 & 2.27 & 73.90 & 2.51 \\
\hline Zeralenone & 25 & 82.19 & 1.28 & 83.99 & 1.13 & 77.30 & 5.57 \\
\hline a-zearalenol & 100 & 79.09 & 1.90 & 82.70 & 1.83 & 74.43 & 3.72 \\
\hline$\beta$-zearalenol & 100 & 75.34 & 3.66 & 78.88 & 5.47 & 68.81 & 10.76 \\
\hline
\end{tabular}

Table 3 Efficiency of different absorbents towards mycotoxins

\begin{tabular}{|c|c|c|c|c|c|c|c|c|c|c|c|c|c|}
\hline \multirow[t]{3}{*}{ Mycotoxin } & \multirow{3}{*}{$\begin{array}{l}\text { Fortification } \\
\text { level }(\mu \mathrm{g} / \mathrm{kg})\end{array}$} & \multicolumn{12}{|c|}{ Recovery (\%) } \\
\hline & & \multicolumn{2}{|c|}{$\begin{array}{l}25 \mathrm{mg} \\
\text { anh. } \mathrm{MgSO}_{4}\end{array}$} & \multicolumn{2}{|c|}{$\begin{array}{l}50 \mathrm{mg} \\
\text { anh. } \mathrm{MgSO}_{4}\end{array}$} & \multicolumn{2}{|c|}{$25 \mathrm{mg}$ PSA } & \multicolumn{2}{|c|}{$50 \mathrm{mg}$ PSA } & \multicolumn{2}{|c|}{$25 \mathrm{mg} \mathrm{C}_{18}$} & \multicolumn{2}{|c|}{$50 \mathrm{mg} \mathrm{C}_{18}$} \\
\hline & & Aver & $\% \mathrm{RSD}$ & Aver & $\% \mathrm{RSD}$ & Aver & $\% \mathrm{RSD}$ & Aver & $\% \mathrm{RSD}$ & Aver & $\% \mathrm{RSD}$ & Aver & $\%$ RSD \\
\hline Aflatoxin $B_{1}$ & 5 & 106.06 & 1.22 & 111.84 & 1.17 & 104.15 & 4.11 & 100.26 & 2.47 & 120.74 & 1.23 & 125.24 & 1.18 \\
\hline Aflatoxin $B_{2}$ & 5 & 103.37 & 2.31 & 103.88 & 2.23 & 95.57 & 1.81 & 89.05 & 1.94 & 103.32 & 0.67 & 103.93 & 2.87 \\
\hline Aflatoxin $G_{1}$ & 5 & 102.95 & 1.32 & 102.16 & 2.12 & 90.29 & 1.08 & 81.60 & 2.30 & 104.02 & 1.13 & 103.96 & 1.72 \\
\hline Aflatoxin $G_{2}$ & 5 & 103.90 & 2.01 & 104.22 & 3.34 & 96.54 & 2.01 & 89.49 & 1.25 & 105.28 & 0.79 & 105.32 & 2.81 \\
\hline Deoxynivalenol & 100 & 92.81 & 0.77 & 92.48 & 1.74 & 87.51 & 1.53 & 80.54 & 1.35 & 92.03 & 1.01 & 92.65 & 0.37 \\
\hline Fumonisin $B_{1}$ & 100 & N.D & N.C & N.D & N.C & N.D & N.C & N.D & N.C & 101.38 & 3.47 & 95.54 & 1.31 \\
\hline Fumonisin $B_{2}$ & 100 & N.D & N.C & N.D & N.C & N.D & N.C & N.D & N.C & 104.51 & 6.66 & 96.74 & 4.17 \\
\hline Ochratoxin A & 20 & 110.67 & 2.97 & 106.19 & 1.67 & 14.88 & 7.65 & 15.25 & 19.65 & 112.30 & 2.95 & 112.29 & 3.79 \\
\hline T-2 toxin & 100 & 100.20 & 1.07 & 100.99 & 0.44 & 102.26 & 0.89 & 97.40 & 3.02 & 101.81 & 0.55 & 102.00 & 0.53 \\
\hline HT-2 toxin & 100 & 95.73 & 1.18 & 98.29 & 1.46 & 89.20 & 3.11 & 84.03 & 3.86 & 98.20 & 2.07 & 97.10 & 0.88 \\
\hline Zeralenone & 25 & 104.73 & 2.88 & 103.42 & 1.21 & 62.75 & 4.82 & 46.25 & 7.96 & 104.47 & 2.37 & 102.41 & 2.05 \\
\hline a-zearalenol & 100 & 101.53 & 2.46 & 102.72 & 2.63 & 60.04 & 4.04 & 39.36 & 4.45 & 103.14 & 1.57 & 102.33 & 1.39 \\
\hline$\beta$-zearalenol & 100 & 99.26 & 1.18 & 99.41 & 3.05 & 52.71 & 8.64 & 36.99 & 20.95 & 96.41 & 1.79 & 98.72 & 1.05 \\
\hline
\end{tabular}

N.D Not detected, N.C not calculated

such as cereals, fish products, and Korean soybean paste. Finally, the immunoaffinity column (IAC) is the last purification and extraction method for mycotoxins, which has been superior to the other two methods in establishing the analytical conditions under the same purification conditions [21]. However, this method did not react with OTB, sterigmatocystin, and 15-acetyldeoxynivalenol. Therefore, the IAC method has disadvantages that must be used after confirming the cross-reactivity with each mycotoxin to be analyzed, and it is difficult to use because of the high purchase price. With these results, in this study, we decided to analyze 13 different kinds of mycotoxins from Korean feedstuffs using the QuEChERS method.

\section{Method validation}

According to the CODEX and SANTE guideline, the limit of detection (LOD) is defined as the minimum analyte 
concentration based on a signal-to-noise $(\mathrm{S} / \mathrm{N})$ ratio of $3: 1$, and the limit of quantitation (LOQ) on an $\mathrm{S} / \mathrm{N}$ ratio of 9:1 These parameters were calculated by injection of neat solvent standard solution at different concentration levels. MLOD and MLOQ, applied to the pre-treatment method, are shown in Additional file 1: Table S5.

Linearity was tested by the evaluation of determination coefficients $\left(R^{2}\right)$. Linear range was estimated for curves prepared a neat solvent, as well as for spiked extracts and spiked samples (Additional file 1: Table S6). The target value for acceptability of mycotoxin curves was an $\mathrm{R}^{2}>0.99$, and recovery tests were all matrix-matched calibration curves prepared for two analyzed matrices. Matrix effects (ME\%) compared curves for neat solvent ESTD calibration, and matrix-matched ESTD calibration were obtained using five concentration levels of standard mycotoxin solutions (Additional file 1: Figure S2). Almost all target mycotoxins showed signal enhancement, and fumonisin B1 (FB1) reacted differently depending on the matrix. However, fumonisin B2 (FB2) displayed signal suppression.

Finally, control samples (5.0 g $\pm 0.1 \mathrm{~g}$ ) of freeze-dried bean and maize were analyzed and results were within the acceptable range of recoveries (70-120\%) (Additional file 1: Figure S3a and b, Table 4).

\section{Measurement of 13 mycotoxins in Korean feedstuff samples}

Measurements of the 13 residual mycotoxins in 39 Korean feedstuff samples are shown in Table 5. All measurements showed an RSD of less than 20\%, confirming the reliability of the analysis (Table 5). The most frequently detected mycotoxins were FB1, DON, FB2, and ZEN with detections in 17, 16, 16, and 14 of 39 samples, respectively. In addition, AFB2, T-2, and HT-2 were detected in one of the 39 samples. Nine samples showed detectable amounts of mycotoxins, and four samples displayed three 3 mycotoxins. In the sample that showed AFB2, DON was simultaneously detected. Interestingly, $\mathrm{DON}, \mathrm{FB} 1, \mathrm{FB} 2$, and $\mathrm{ZEN}$ were detected at the same time. Therefore, DON, FB1, FB2, and ZEN appear to be more important contaminants in feedstuff in Korea than contamination with aflatoxins.

Further, amounts of these mycotoxins were in the range of $0.0447-4.8073 \mathrm{mg} / \mathrm{kg}$ for DON, $0.0418-18.0943 \mathrm{mg} /$ $\mathrm{kg}$ for FB1, $0.0181-5.3227 \mathrm{mg} / \mathrm{kg}$ for FB2 and $0.0200-$ $4.5617 \mathrm{mg} / \mathrm{kg}$ for ZEN. Stall food samples showed the highest levels of DON, FB1, FB2, and ZEN were 4.8073, $18.0943,5.3227$, and $4.5617 \mathrm{mg} / \mathrm{kg}$, respectively. Also, AFB2 was detected at $0.0018 \mathrm{mg} / \mathrm{kg}, \mathrm{T}-2$ at $0.0236 \mathrm{mg} /$ $\mathrm{kg}$, and HT-2 at $0.0168 \mathrm{mg} / \mathrm{kg}$. AFB2 concentrations did not reach the current Korean MRLs of $10 \mu \mathrm{g} / \mathrm{kg}$, which is for the total amount of aflatoxin in compound feed, and
$50 \mu \mathrm{g} / \mathrm{kg}$, the total amount of aflatoxin for single constituents of feedstuffs.

However, the Korean government currently applies MRLs as recommended levels, and feed producers are not obligated to meet these levels. Currently, Korean recommended MRLs are the same for T-2 and HT-2 and did not exceed this value in any tested sample. In contrast, the Korean recommended MRL for feedstuffs for FB1 and FB2 is defined as the sum of the two toxins. This MRL is $60 \mathrm{mg} / \mathrm{kg}$ for a single ingredient. MRLs for formulated feedstuffs for rearing livestock and pets, young ruminants, and ruminants are 5, 20, and $50 \mathrm{mg} / \mathrm{kg}$, respectively. Thus, our results for the sum of FB1 and FB2 show that three samples in 39 samples were exceeded MRLs (Table 5).

Similarly, MRLs for Korean feedstuffs for DON are $0.9 \mathrm{mg} / \mathrm{kg}$ for rearing livestock and pets, $2.0 \mathrm{mg} / \mathrm{kg}$ for young livestock, and $10.0 \mathrm{mg} / \mathrm{kg}$ for single materials for feedstuff. Our results did not exceed these levels. MRL values of for $\mathrm{ZEN}$ in formulated feedstuffs for rearing pigs and ruminants, and for single materials for feedstuffs are not exceeded at the levels of $0.25,0.5$, and $3.0 \mathrm{mg} / \mathrm{kg}$, respectively. One of 39 samples in the current study exceeded MRLs. Appropriate management of mycotoxins, FUMs and DON, in Korean feedstuffs should include proper monitoring.

Results of monitoring mycotoxins at the national level are continuously reported [29]. Eight mycotoxins (four AFs, FB1 and FB2, OTA and ZEN) were analyzed and the sum of FB1 and FB2 in 35 of 127 samples ranged from $4.8-738.5 \mu \mathrm{g} / \mathrm{kg}$. The highest concentrations were observed in maize $(738 \mu \mathrm{g} / \mathrm{kg})$ and adlay $(103 \mu \mathrm{g} / \mathrm{kg})$ [29].

In another report, AFs, OTA, ZEN, and FUM were frequently detected in Korean soybean paste (Doenjang), and FUM was detected in eight of 30 commercially available foodstuffs [21]. FB1 and FB2 were detected in 16 of 30 homemade Doenjang [21]. Thus, when consuming such Doenjang proper analysis of mycotoxins should be considered. In the present study, AFB1 was detected at a level of $4.45 \mu \mathrm{g} / \mathrm{kg}$, which may be unhealthy. Also, detection of AFG1 and AFG2 is not reported, and Aspergillus flavus rather than A. parasiticus are likely involved in contamination of aflatoxin in Korean Doenjang. A. flavus appears to produce more AFB1 and AFB2 than AFG1 and AFG2 [30, 31].

In China, a total of 160 feedstuff samples, consisting of 76 maize and 84 soybean meals, were analyzed using an LC-MS/MS analytical system for 26 mycotoxins and none of these samples showed concentrations of AFB1, T-2, and ZEN that exceeded MRLs [32]. Maize (13.1\%) and soybean (2.4\%) meal samples exceeded the maximum tolerance of DON for formulated pig feed of 
Table 4 Recovery $(n=5)$ of mycotoxins obtained from QuEChRES sample preparation

\begin{tabular}{|c|c|c|c|c|c|c|c|}
\hline \multirow[t]{3}{*}{ Mycotoxin } & \multirow{3}{*}{$\begin{array}{l}\text { Fortification level }(\mu \mathrm{g} / \\
\mathrm{kg})\end{array}$} & \multicolumn{6}{|c|}{ Recovery (\%) } \\
\hline & & \multicolumn{3}{|l|}{ Maize } & \multicolumn{3}{|l|}{ Bean } \\
\hline & & Aver & STDEV & $\%$ RSD & Aver & STDEV & \%RSD \\
\hline \multirow[t]{3}{*}{ Aflatoxin $B_{1}$} & 5 & 83.7 & 2.1 & 2.5 & 83.7 & 3.2 & 3.8 \\
\hline & 10 & 86.3 & 2.5 & 2.9 & 78.8 & 1.5 & 1.9 \\
\hline & 50 & 86.3 & 3.3 & 3.8 & 85.5 & 1.0 & 1.2 \\
\hline \multirow[t]{3}{*}{ Aflatoxin $B_{2}$} & 5 & 77.0 & 5.2 & 6.8 & 85.3 & 3.3 & 3.9 \\
\hline & 10 & 81.5 & 1.1 & 1.3 & 87.0 & 0.7 & 0.8 \\
\hline & 50 & 83.7 & 1.9 & 2.2 & 86.6 & 0.7 & 0.9 \\
\hline \multirow{3}{*}{ Aflatoxin $\mathrm{G}_{1}$} & 5 & 71.0 & 2.4 & 3.4 & 77.8 & 2.0 & 2.5 \\
\hline & 10 & 79.9 & 0.6 & 0.8 & 85.4 & 1.2 & 1.4 \\
\hline & 50 & 86.1 & 1.8 & 2.1 & 87.2 & 0.1 & 0.2 \\
\hline \multirow[t]{3}{*}{ Aflatoxin $G_{2}$} & 5 & 87.4 & 6.2 & 7.1 & 82.8 & 1.0 & 1.3 \\
\hline & 10 & 88.9 & 3.0 & 3.3 & 88.8 & 2.1 & 2.4 \\
\hline & 50 & 88.4 & 2.0 & 2.3 & 83.1 & 0.9 & 1.1 \\
\hline \multirow[t]{3}{*}{ Deoxynivalenol } & 100 & 89.0 & 10.0 & 11.3 & 100.5 & 2.1 & 2.1 \\
\hline & 200 & 76.7 & 2.7 & 3.5 & 87.0 & 3.4 & 3.9 \\
\hline & 1000 & 78.5 & 5.5 & 6.9 & 74.9 & 3.9 & 5.2 \\
\hline \multirow[t]{3}{*}{ Fumonisin $B_{1}$} & 100 & 99.0 & 3.3 & 3.4 & 86.7 & 3.2 & 3.6 \\
\hline & 200 & 73.9 & 1.3 & 1.8 & 78.1 & 2.2 & 1.5 \\
\hline & 1000 & 75.0 & 1.1 & 1.4 & 72.1 & 1.1 & 1.5 \\
\hline \multirow[t]{3}{*}{ Fumonisin $B_{2}$} & 100 & 112.3 & 2.9 & 2.6 & 115.6 & 4.1 & 3.5 \\
\hline & 200 & 80.9 & 7.5 & 9.3 & 88.0 & 2.6 & 2.9 \\
\hline & 1000 & 73.3 & 1.5 & 2.0 & 73.1 & 1.5 & 2.0 \\
\hline \multirow[t]{3}{*}{ Ochratoxin A } & 20 & 106.3 & 1.8 & 1.7 & 96.4 & 1.8 & 1.9 \\
\hline & 40 & 76.6 & 1.3 & 1.7 & 89.3 & 1.7 & 1.8 \\
\hline & 200 & 88.1 & 0.6 & 0.7 & 82.5 & 1.0 & 1.2 \\
\hline \multirow[t]{3}{*}{ T-2 toxin } & 100 & 86.7 & 2.9 & 3.3 & 89.3 & 2.3 & 2.6 \\
\hline & 200 & 90.0 & 1.2 & 1.3 & 94.7 & 1.2 & 1.3 \\
\hline & 1000 & 88.7 & 1.6 & 1.8 & 93.7 & 1.9 & 2.0 \\
\hline \multirow[t]{3}{*}{ HT-2 toxin } & 100 & 72.8 & 3.2 & 4.4 & 86.5 & 2.96 & 3.1 \\
\hline & 200 & 83.2 & 1.7 & 2.0 & 92.2 & 3.9 & 4.2 \\
\hline & 1000 & 89.6 & 2.4 & 2.7 & 90.2 & 3.9 & 1.2 \\
\hline \multirow[t]{3}{*}{ Zeralenone } & 25 & 70.1 & 4.2 & 5.9 & 88.5 & 2.8 & 3.2 \\
\hline & 50 & 83.3 & 3.2 & 3.8 & 84.1 & 3.6 & 4.3 \\
\hline & 100 & 89.4 & 1.9 & 2.1 & 80.5 & 1.9 & 2.4 \\
\hline \multirow[t]{3}{*}{ a-zearalenol } & 100 & 75.2 & 3.4 & 4.5 & 111.6 & 2.7 & 2.4 \\
\hline & 200 & 82.8 & 2.5 & 3.0 & 97.8 & 7.0 & 7.1 \\
\hline & 1000 & 86.3 & 3.3 & 3.8 & 88.7 & 2.0 & 2.2 \\
\hline \multirow[t]{3}{*}{$\beta$-zearalenol } & 100 & 94.1 & 6.0 & 6.4 & 83.6 & 2.5 & 3.0 \\
\hline & 200 & 86.3 & 1.0 & 1.1 & 84.0 & 3.5 & 4.1 \\
\hline & 1000 & 84.4 & 3.4 & 4.0 & 84.4 & 1.7 & 2.0 \\
\hline
\end{tabular}




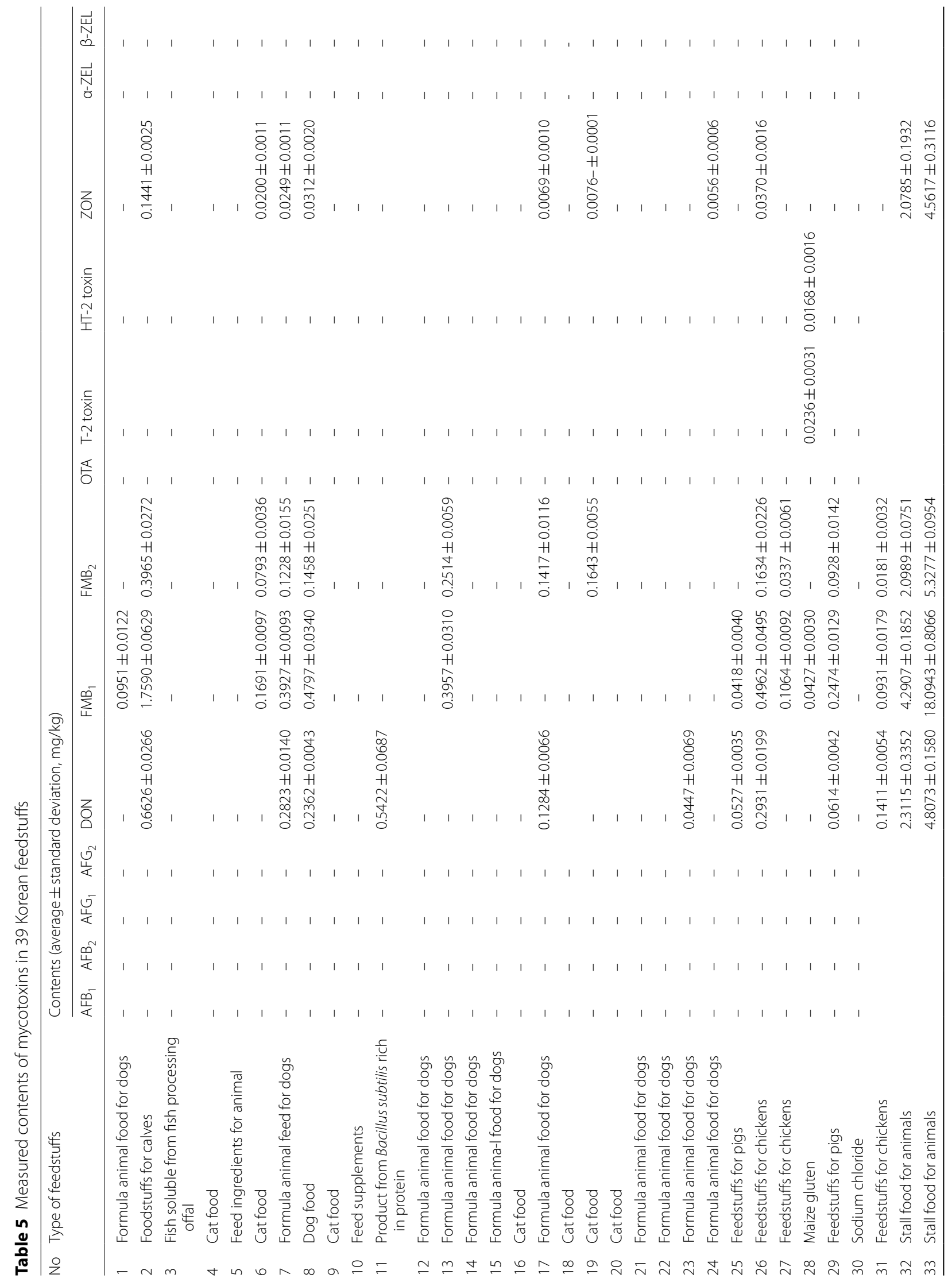




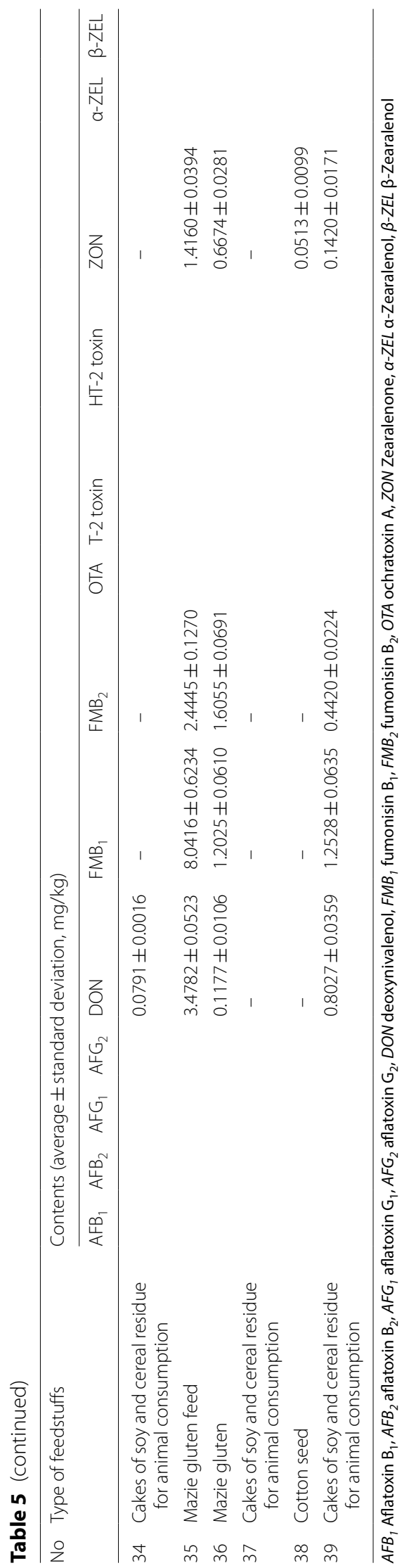


$1000 \mu \mathrm{g} / \mathrm{kg}$ [32]. Mycotoxin contamination varies by country. Further, weather condition, such as temperature and humidity, may be key factors for the fungal production of mycotoxins [33, 34].

\section{Supplementary Information}

The online version contains supplementary material available at https://doi. org/10.1186/s13765-021-00602-9.

Additional file 1: Figure S1. Diagram of the employed sample preparation for the analysis of mycotoxins. Figure S2. Matrix effects of bean and maize as shown as signal suppression and enhancement. Figure S3. Average recovery $(n=5)$ of mycotoxins obtained from QuEChRES sample preparation (a: Bean, B: Maize). Table S1. Concentrate ranges of each mycotoxin for linearity. Table S2. Matrix-matched calibration curve preparation. Table S3. Peak intensity (Area) with final dilution. Table S4. Recovery by two types of absorbents after extraction towards mycotoxins. Table S5. Calibration ranges, MLOD and MLOQ of the optimized analytical method. Table S6. Determination coefficient $\left(R^{2}\right)$ for the targeted mycotoxins in two validated raw feed material-based matrices such as bean and maize

\section{Acknowledgements}

Not available.

\section{Authors' contributions}

SC, SL, and JM designed the experiments and wrote the manuscript. HJ, MP, $\mathrm{HH}$, and $\mathrm{HJ}$. performed all the experiments. $\mathrm{HJ}, \mathrm{SL}$, and JM performed data analysis. All authors read and approved the final manuscript.

\section{Funding}

This work was supported by Korea Institute of Planning and Evaluation for Technology in Food, Agriculture and Forestry (IPET) through Agro and Livestock Products Safety Flow Management Technology Development Program, funded by Ministry of Agriculture, Food and Rural Affairs (MAFRA) (31871-3).

\section{Availability of data and materials} Yes.

\section{Declarations}

\section{Competing interests}

The authors declare that they have no competing interests.

\begin{abstract}
Author details
${ }^{1}$ Hansalim Agro-Food Analysis Center, Hankyong National University Industry Academic Cooperation Foundation, Suwon 16500, Republic of Korea. ${ }^{2}$ School of Urban and Environmental Engineering, Ulsan National Institute of Science and Technology (UNIST), Ulsan 44919, Republic of Korea. ${ }^{3}$ Department of Applied Biosciences, Kyungpook National University, Daegu 41566, Republic of Korea. ${ }^{4}$ Department of Plant Life and Environmental Sciences, Hankyong National University, Anseong 17579, Republic of Korea.
\end{abstract}

Received: 23 November 2020 Accepted: 26 February 2021 Published online: 05 April 2021

\section{References}

1. Fung F, Clark RF (2004) Health effects of mycotoxins: a toxicological overview. J Toxicol Clin Toxicol 42:217-234. https://doi.org/10.1081/clt-12003 0947

2. Misihairabgwi JM, Ezekiel CN, Sulyok M, Shephard GS, Krska R (2019) Mycotoxin contamination of foods in Southern Africa: a 10-year review (2007-2016). Crit Rev Food Sci Nutr 59:43-58. https://doi.org/10.1080/ 10408398.2017.1357003
3. Pitt JI, Miler JD (2017) A concise history of mycotoxin research. J Agric Food Chem 65:7021-7033. https://doi.org/10.1021/acs.jafc.6b04494

4. Stoev SD (2013) Food safety and increasing hazard of mycotoxin occurrence in foods and feeds. Crit Rev Food Sci Nutr 53:887-901. https://doi. org/10.1080/10408398.2011.571800

5. Roze LV, Laivenieks M, Hong SY, Wee J, Wong SS, Vanos B, Awad D, Ehrlich KC, Linz JE (2015) Aflatoxin biosynthesis is a novel source of reactive oxygen species-a potential redox signal to initiate resistance to oxidative stress? Toxins 7:1411-1430. https://doi.org/10.3390/toxins7051411

6. Wang Y, Wang L, Liu F, Wang Q, Selvaraj JN, Xing F, Zhao Y, Liu Y (2016) Ochratoxin A producing fungi, biosynthetic pathway and regulatory mechanisms. Toxins 8:83. https://doi.org/10.3390/toxins8030083

7. Calado T, Venâncio A, Abrunhosa L (2014) Irradiation for mold and mycotoxin control: a review. Compr Rev Food Sci F 13:1049-1061. https://doi. org/10.1111/1541-4337.12095

8. Ghanem I, Orfi M, Shamma M (2008) Effect of gamma radiation on the inactivation of aflatoxin B1 in food and feed crops. Braz J Microbiol 39:787-791. https://doi.org/10.1590/S1517-83822008000400035

9. D'Mello JPF, Macdonald AMC, Postel D, Dijksma WTP, Dujardin A, Placinta CM (1998) Pesticide use and mycotoxin production in Fusarium and Aspergillus phytopathogens. Eur J Plant Pathol 104:741-751. https://doi. org/10.1023/A:1008621505708

10. Gonçalves A, Gkrillas A, Dorne JL, Dall'Asta C, Palumbo R, Lima N, Battilani P, Venâncio A, Giorni P (2019) Pre-and Postharvest strategies to minimize mycotoxin contamination in the rice food chain. Compr Rev Food Sci F 18:441-454. https://doi.org/10.1111/1541-4337.12420

11. Moo YS, Lee HS, Lee SE (2018) Inhibitory effects of three monoterpenes from ginger essential oil on growth and aflatoxin production of Aspergillus flavus and their gene regulation in aflatoxin biosynthesis. Appl Biol Chem 61:243-250. https://doi.org/10.1007/s13765-018-0352-x

12. Prakash B, Kedia A, Mishra PK, Dubey NK (2015) Plant essential oils as food preservatives to control moulds, mycotoxin contamination and oxidative deterioration of agri-food commodities-potentials and challenges. Food Control 47:381-391. https://doi.org/10.1016/j.foodcont.2014.07.023

13. Choi H, Lee BH, Moon YS, Kim K, Lee HS, Lee SE (2017) Antifungal and antiaflatoxigenic effects of a fumigant, ethanedinitrile, on Aspergillus flavus. Appl Biol Chem 60:473-476. https://doi.org/10.1007/ s13765-017-0301-0

14. Kim HM, Kwon H, Kim K, Lee SE (2018) Antifungal and antiaflatoxigenic activities of 1,8-cineole and $t$-cinnamaldehyde on Aspergillus flavus. Appl Sci 8:1655. https://doi.org/10.3390/app8091655

15. Karlovsky P, Suman M, Berthiller F, De Meester J, Eisenbrand G, Perrin I, Oswald IP, Speijers G, Chiodini A, Recker T, Dussort P (2016) Impact of food processing and detoxification treatments on mycotoxin contamination. Mycotoxin Res 32:179-205. https://doi.org/10.1007/ s12550-016-0257-7

16. Piva GFP, Galvano FRD, Pietri AAP, Piva ARD (1995) Detoxification methods of aflatoxins: a review. Nutr Res 15:767-776. https://doi.org/10.1016/ 0271-5317(95)00042-H

17. Gomaa MNE, Ayesh AM, Abdel Galil MM, Naguib K (1997) Effect of high pressure ammoniation procedure on the detoxification of aflatoxins. Mycotoxin Res 13:23-34. https://doi.org/10.1007/BF02945059

18. Agbetiameh D, Ortega-Beltran A, Awuah RT, Atehnkeng J, Islam M, Callicott KA, Cotty PJ, Bandyopadhyay R (2019) Potential of atoxigenic Aspergillus flavus vegetative compatibility groups associated with maize and groundnut in Ghana as biocontrol agents for aflatoxin management. Front Microbiol 10:2069. https://doi.org/10.3389/fmicb.2019.02069

19. Tayel AA, El-Tras WF, Moussa SH, El-Agamy MA (2013) Antifungal action of Pichia anomala against aflatoxigenic Aspergillus flavus and its application as a feed supplement. J Sci Food Agric 93:3259-3263. https://doi.org/10. 1002/jsfa.6169

20. Ji C, Fan Y, Zhao L (2016) Review on biological degradation of mycotoxins. Anim Nutr 2:127-133. https://doi.org/10.1016/j.aninu.2016.07.003

21. Woo SY, Ryu SY, Tian F, Lee SY, Park SB, Chun HS (2019) Simultaneous determination of twenty mycotoxins in the Korean soybean paste Doenjang by LC-MS/MS with immunoaffinity cleanup. Toxins 11:594. https:// doi.org/10.3390/toxins 11100594

22. Zhang B, Chen X, Han SY, Li M, Ma TZ, Sheng WJ, Zhu X (2018) Simultaneous analysis of 20 mycotoxins in grapes and wines from Hexi Corridor Region (China); based on a QuEChERS-UHPLC-MS/MS method. Molecules 23:1926. https://doi.org/10.3390/molecules23081926 
23. Sun J, Li X, Zhang Y, Hu X, Wu L, Wang B (2016) QuEChERS purification combined with ultrahigh-performance liquid chromatography tandem mass spectrometry for simultaneous quantification of 25 mycotoxins in cereals. Toxins 8:375. https://doi.org/10.3390/toxins8120375

24. Anukul N, Vangnai K, Mahakarnchanakul W (2013) Significance of regulation limits in mycotoxin contamination in Asia and risk management programs at the national level. J Food Drug Anal 21:227-241. https://doi. org/10.1016/j.jfda.2013.07.009

25. Agriopoulou S, Stamatelopoulou E, Varzakas T (2020) Advances in occurrence, importance, and mycotoxin control strategies: prevention and detoxification in foods. Foods 9:137. https://doi.org/10.3390/foods90201 37

26. Chen MT, Hsu YH, Wang TS, Chien SW (2016) Mycotoxin monitoring for commercial foodstuffs in Taiwan. J Food Drug Anal 24:147-156. https:// doi.org/10.1016/j.jfda.2015.06.002

27. Meyer H, Skhosana ZD, Motlanthe M, Louw W, Rohwer E (2019) Long term monitoring (2014-2018) of multi-mycotoxins in South African commercial maize and wheat with a locally developed and validated LC-MS/ MS method. Toxins 11:271. https://doi.org/10.3390/toxins11050271

28. Tolosa J, Barba FJ, Font G, Ferrer E (2019) Mycotoxin incidence in some fish products: QuEChERS methodology and liquid chromatography linear ion trap tandem mass spectrometry approach. Molecules 24:527. https:// doi.org/10.3390/molecules24030527

29. Yang Y, Lee HH, Kim AG, Ryu KY, Choi SY, Seo DR, Seo KW, Cho BS (2019) Survey of mycotoxin contamination in grains and grain products. J Food Hyg Saf 34:205-211. https://doi.org/10.13103/JFHS.2019.34.2.205
30. Fakruddin M, Chowdhury A, Hossain MN, Ahmed MM (2015) Characterization of aflatoxin producing Aspergillus flavus from food and feed samples. SpringerPlus 4:159. https://doi.org/10.1186/s40064-015-0947-1

31. Casquete R, Benito MJ, de Guía CM, Ruiz-Moyano S, Martín A (2017) The growth and aflatoxin production of Aspergillus flavus strains on a cheese model system are influenced by physicochemical factors. J Dairy Sci 100:6987-6996. https://doi.org/10.3168/jds.2017-12865

32. Wang RG, Su XO, Cheng FF, Wang PL, Fan X, Zhang W (2015) Determination of 26 mycotoxins in feedstuffs by multifunctional clean-up column and liquid chromatography-tandem mass spectrometry. Chin J Anal Chem 43:264-270. https://doi.org/10.1016/S1872-2040(15)60807-6

33. Cotty P, Jaime R (2007) Influence of climate on aflatoxin producing fungi and aflatoxin contamination. Int J Food Microbiol 119:109-115. https:// doi.org/10.1016/j.ijfoodmicro.2007.07.060

34. Joo Y, Ok HE, Lim J, Lee SY, Jang SK, Park KH, Chun HS (2019) A statistical model for determining zearalenone contamination in rice (Oryza sativa L.) at harvest and its prediction under different climate change scenarios in South Korea. Appl Biol Chem 62:38. https://doi.org/10.1186/ s13765-019-0447-z

\section{Publisher's Note}

Springer Nature remains neutral with regard to jurisdictional claims in published maps and institutional affiliations.

\section{Submit your manuscript to a SpringerOpen ${ }^{\odot}$ journal and benefit from:}

- Convenient online submission

- Rigorous peer review

- Open access: articles freely available online

- High visibility within the field

- Retaining the copyright to your article

Submit your next manuscript at $\boldsymbol{\Delta}$ springeropen.com 